\title{
(息)
}

Citation:

Southby, K and Gamsu, M (2018) Factors affecting general practice collaboration with voluntary and community sector organisations. Health Soc Care Community. ISSN 1365-2524 DOI: https://doi.org/10.1111/hsc. 12538

Link to Leeds Beckett Repository record:

https://eprints.leedsbeckett.ac.uk/id/eprint/4651/

Document Version:

Article (Accepted Version)

The aim of the Leeds Beckett Repository is to provide open access to our research, as required by funder policies and permitted by publishers and copyright law.

The Leeds Beckett repository holds a wide range of publications, each of which has been checked for copyright and the relevant embargo period has been applied by the Research Services team.

We operate on a standard take-down policy. If you are the author or publisher of an output and you would like it removed from the repository, please contact us and we will investigate on a case-by-case basis.

Each thesis in the repository has been cleared where necessary by the author for third party copyright. If you would like a thesis to be removed from the repository or believe there is an issue with copyright, please contact us on openaccess@leedsbeckett.ac.uk and we will investigate on a case-by-case basis. 


\section{Factors affecting General Practice collaboration with voluntary and community sector organisations}

\section{Abstract}

Collaborative working between general practice (GP) and voluntary and community sector (VCS) organisations is increasingly championed as a means of primary care doing more with less and of addressing patients' 'wicked problems'. This paper aims to add to the knowledge base around collaborative practice between GPs and VCS organisations by examining the factors that aid or inhibit such collaboration. A case study design was used to examine the lived-experience of GPs and VCS organisations working collaboratively. Four cases, each consisting of a GP and a VCS organisation with whom they work collaboratively, were identified. Interviews $(n=18)$ and a focus group $(n=1)$ were conducted with staff within each organisation. Transcribed data were analysed thematically. Whilst there are similarities across cases in their use of, for example, Health Trainers and social prescribing, the form and function of GP-VCS collaborations were unique to their local context. The identified factors affecting GP-VCS collaboration reflect those found in previous service evaluations and the broader literature on partnership working; shared understanding, time and resources, trust, strong leadership, operational systems and governance, and the 'negotiation' of professional boundaries. Whilst the current political environment may represent an opportunity for collaborations to develop, there are issues yet be to resolved before collaboration - especially more holistic and integrated approaches - becomes systematically embedded into practice.

\section{Key words}


General Practice; voluntary sector; Case study research; health policy; health services research; inter-organisational working

\section{What is known about the topic?}

- GP-VCS collaboration is promoted to relieve mounting pressures on primary care and improve outcomes for patients.

- Collaboration can take many forms and has been understood as a cost-effective solution to society's 'wicked problems' for many years.

- However, the established literature on collaboration and a number of service evaluations exploring GPs and VCS organisations provides little evidence to inform GP-VCS collaborations in practice.

\section{What this paper adds?}

- GP-VCS collaborations adapt to their local contexts.

- GP-VCS collaborations are affected by the same overlapping and interconnected factors as other cross-sector working.

- Current policy is supportive of GP-VCS collaboration. However, the reasons why collaborations do not occur are yet to be overcome.

\section{Introduction}

General practice (GP) - especially in socio-economically deprived communities - is beginning to buckle under mounting pressures (Baird et al., 2016; Primary Care Workforce Commission, 2015). Patients increasingly look to their GP to resolve issues with a distinct social dimensions or arising directly from their social situation, which is often beyond the capacity of GP staff (GPs at the Deep End, 2014; Kimberlee, 2013). To the detriment of 
patient care, psycho-social problems that are the result of underlying socio-economic determinants of health may be repackaged as 'medical' issues and treated with pharmacological interventions (Cawston, 2011; Grant et al., 2000).

Linking the resources of GPs with those found in the community is advocated by policy makers (NHS England, 2014, 2016), clinicians (GPs at the Deep End, 2010; Primary Care Workforce Commission, 2015), and researchers (Bungay \& Clift, 2010; Kimberlee, 2015; Lamb et al., 2012) as a more effective means of addressing patients' psycho-social health needs. Voluntary and community sector (VCS) organisations that are embedded in their communities can "have an input beyond what statutory services can achieve" (NHS England, 2014, p. 14; 2016). Recognising local assets is particularly important in areas of high deprivation, where people may be less empowered, have complex needs, poorer health literacy, and be less willing to access support unless it is local (Swindley, 2015).

Interventions delivered through collaborations between GPs and VCS organisations have been shown to benefit patients' physical, mental, and social health and wellbeing (Age UK Yorkshire \& Humber, 2012; Dayson et al., 2013; Friedli et al., 2012; Kimberlee et al., 2014; Pavey et al., 2011). Some evidence points to patient benefits over and above routine care (Friedli et al., 2012), although this is not conclusive (Grant et al., 2000). Socially orientated approaches delivered through GP-VCS collaborations may broaden community capacity (Friedli et al., 2012) and empower patients to better manage their own health and make more appropriate use of health services (Dayson et al., 2013; Kimberlee et al., 2014; Maughan et al., 2016). Whilst there is not yet sufficient evidence to conclusively judge the value for money of linking patients with community resources (Bickerdike et al., 2017), GP-VCS collaborations may have direct and indirect economic benefits (Dayson \& Bashir, 2014; Kimberlee et al., 2014; Maughan et al., 2016). 
However, despite the professed benefits of GP-VCS collaboration, there is little good quality evidence to inform collaboration (Bickerdike et al., 2017) and concerns exist around optimal implementation processes (Mossabir et al., 2015). Research on factors underpinning joint working has focused on inter-organisational issues and little attention has been paid to the frontline staff who are expected to work together (Aveling \& Jovchelovitch, 2014; Lindsay \& Dutton, 2012). The aim of this paper is not to discuss the professed merits of GP-VCS collaboration to address the socio-economic determinants underpinning health inequalities. Rather, the focus in on examining the factors identified by GP and VCS organisations that aid or inhibit their collaborative working. This will be achieved by reflecting on the experience of GP and VCS organisations already working collaboratively to address health inequalities in socio-economically deprived communities in one northern city in England. In doing so, the paper will add to the growing knowledge base around GP-VCS collaboration.

\section{Literature review}

\section{Collaboration in public service delivery}

Since the squeezing of public finances in the 1970's, cross-sector collaboration between government, business, non-profit organisations, and communities has been promoted as a necessary and effective strategy for addressing many of society's most difficult challenges (Bryson et al., 2006). Collaborations are championed as ways of delivering more with less (Lowndes \& Skelcher, 1998) and addressing the 'wicked issues' that span organisational boundaries (Hudson \& Hardy, 2002) by combining the knowledge, resources, and skills of partners to create a whole that is more than the sum of its constituent elements (Slater et al., 2007). 
An established literature details the many forms and functions of cross-sector collaborations. Organisations who have nominally increased their communication and co-operation and organisations that have fully integrated to form a new entity represent the two ends of a broad collaboration continuum. Organisations that, to varying degrees, share information and power and co-ordinate activities in order to achieve a shared goal span the middle (Bryson \& Crosby, 2005; Slater et al., 2007). Collaborations can also be fluid, evolving over time in response to internal reflections and learning and the external environment (Slater et al., 2007).

Factors that facilitate or hinder cross sector-collaborations have been identified, including interpersonal relationships (Löffler et al., 2017), operational procedures (Coe \& Barlow, 2010), governance (Lowndes \& Skelcher, 1998), norms and values, and leadership (Douglas, 2009). A proliferation of taxonomies about collaboration describes their inception, development, structure, operation and culmination. Bryson et al. (2006) and Hudson and Hardy (2002), two examples of conceptual frameworks, share similar ideas for understanding cross-sector collaborations. Bryson et al. (2006) suggests the challenge for collaborators is to align around six features - initial conditions, process components, structure and governance, contingencies and constraints, outcomes, accountabilities - such that good things happen in a sustained way. Likewise, Hudson and Hardy (2002) propose six principals for success: acknowledging the need for partnership; clarity and realism of purpose; commitment and ownership; development and maintenance of trust; clear and robust partnership arrangement; and monitoring and reviewing learning.

\section{GP-VCS collaboration}

The most widely understood and promoted conceptualisation of GP-VCS collaboration is 'social prescribing', in which a GP and VCS organisation partner together so that patients are 
linked with sources of non-clinical support in their community through a 'referral' from a clinician (South et al., 2008; White et al., 2017). The term brings together an assortment of activities and service delivery models (White et al., 2017), including arts (Bungay \& Clift, 2010) or exercise (Pedersen et al., 2016) on prescription. Some social prescribing models have patients referred directly from a GP to a VCS organisation. Others involve a 'linking' phase through a third-party (Mossabir et al., 2015). In such cases, it may be that VCS organisations therefore work in parallel with GPs without any explicit links (Mossabir et al., 2015).

Kimberlee (2015) has developed a framework around social prescribing in which GP-VCS collaboration can be understood as 'light', 'medium', or 'holistic'. In progressing from one level to the next - from 'light' to 'medium' to 'holistic' - the medical model of health that traditionally informs GP-VCS relationships is replaced by an increasingly equitable sharing of roles, responsibilities, rights, and rewards. A complimentary approach to understanding variation in GP-VCS collaboration is that described by Whitelaw et al. (2016). Using 'normalisation theory' (May et al., 2007) to explore the interactions between GP and VCS staff, the policies and procedures in place, and the overall context in which interactions take place, collaboration is either 'genuinely embedded' within the working practices of partner organisations, 'adopted' by both organisations but not embedded to the same extent, or 'rejected' by one or both parties (Whitelaw et al., 2016).

A relatively small amount of research has explored operational issues surrounding GP-VCS collaboration. Insights have mainly come from evaluations of services and findings reflect those found in the broader collaboration literature. Cited effective factors to GP-VCS collaboration include understanding of roles (White et al., 2010), organisational capacity (Goldberg et al., 2013; South et al., 2008), awareness of partners capabilities (Grant et al., 
2000), operational procedures (White et al., 2017), trust (Brandling \& House, 2007; Mossabir et al., 2015), organisational (in)stability (Brandling \& House, 2007), evidence base (Bungay \& Clift, 2010), status and power (White et al., 2017), policy and legislative context (Bungay \& Clift, 2010; Whitelaw et al., 2016), staff skills (Mossabir et al., 2015; South et al., 2008; Woodall \& South, 2005), physical proximity (Mossabir et al., 2015; Woodall \& South, 2005), interpersonal relationships (White et al., 2017; White et al., 2010), and leadership (Mossabir et al., 2015; Whitelaw et al., 2016). Of particular importance is reconciling the conflicting medical and social models between GPs and VCS organisations (Aveling \& Jovchelovitch, 2014; Popay et al., 2007; White et al., 2017; Whitelaw et al., 2016).

Collectively, these factors are thought to form a critical mass for sustainability (Whitelaw et al., 2016).

\section{Methodology}

The aim of this research was to identify the factors affecting GP-VCS collaboration in Sheffield, England. Sheffield experiences significant health inequalities and interventions to address the health needs of the most deprived communities, focussing on prevention, are paramount (NHS Commissioners across South and Mid Yorkshire, 2017). The research was part of a larger project, overseen by the Health Inequalities Group within Sheffield Clinical Commissioning Group (CCG), to bring together an 'alliance of the willing' of stakeholders committed to developing a city wide approach to addressing health inequality. The Health Inequalities Group acted as a steering group for the research, contributing to setting research aims and objectives and supporting recruitment.

A case study design was adopted. Case study research is concerned with the complexity and the particular nature of a subject of study (the case) and involves an up-close, in-depth, and detailed examination of that subject (Bryman, 2016). Whilst the findings of individual cases 
themselves may not be generalised, comparing across multiple cases allows overarching themes and theories to emerge.

Four cases, each comprising a GP and a VCS organisation with whom they work to address health inequalities in their local area, were developed. Cases were identified following a purposive, convenience procedure. Twenty-five GPs and six 'community anchor' VCS organisations known to be engaging in collaborative work were identified and invited by letter and follow up telephone call to take part in the research. Four GPs and the VCS organisation with whom they collaborate agreed to take part. More information about the cases is presented in Box 1.

$* * * * * * * * * * * * * * * * * * * * * * *$ INSERT Box 1*********************************1

Qualitative research instruments were used in order to capture the complexity of the 'lived experience' of GP-VCS collaboration. To explore cases 1, 2, and 3, semi-structured interviews (total $n=18$ ) were conducted with a GP, practice manager, and practice nurse in each general practice and a senior manager and two practitioners in each VCS organization. Interviews were conducted face-to-face in the interviewee's place of work. For case 4, a focus group was carried out in the Darnall Primary Care Centre and was attended by GP staff $(n=6)$ and VCS organisation staff $(n=8)$. This convenience sample of participants was able to reach a saturation of themes.

Data were analysed thematically (Braun \& Clarke, 2006) by one researcher using Nvivo. Transcribed audio recordings of the interviews and focus group were read and key information pertinent to the research objectives highlighted into emergent 'codes'. Related codes were grouped together into themes and sub-themes and emerging themes were discussed with the steering group for corroboration. The highest order themes - 'models of collaboration', 'facilitators of collaboration' and 'barriers to collaboration' - are used here as 
subheadings to present the findings. Pertinent quotes from the interviews and focus group are used here to illustrate key points. Quotes are attributed to interview respondents using a number and 'GP staff' or 'VCS staff' to indicate which organisation they represented. Quotes are attributed to focus group participants using 'Focus Group'.

The research was conducted between February and May August 2016. Ethical approval for this work was granted by Leeds Beckett University.

\section{Findings}

Through this research a number of factors affecting GP-VCS collaborations were identified (see Figure 1).

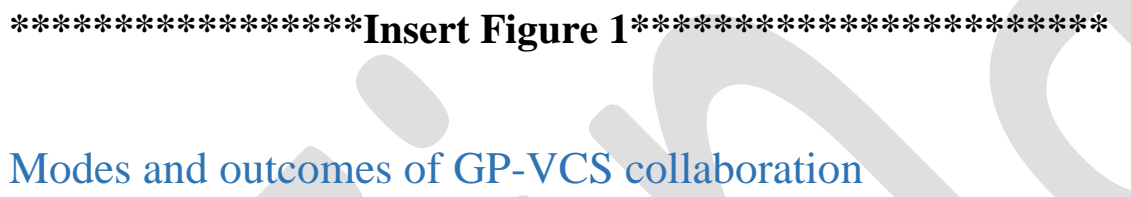

No single model of GP-VCS collaboration was evident. Rather, GPs and VCS organisations developed individual ways of working in accordance with their local context, with some being more collaborative than others.

"I think you've got sort of three tiers. You have surgeries that really buy into it...Then you have a middle slant that sort of they do get it, but they need us when they want to so they refer to on an ad hoc basis... Then there's a cluster of surgeries that just don't engage” (2, VCS staff)

Cases 1, 2, and 3 had mainly transactional relationships; VCS organisations where a referral agency providing a service to GPs. Only Case 4, with their jointly developed Enhanced 
Primary and Community Care scheme, had a more 'holistic' relationship with a shared ethos and process.

A common feature across all cases was social prescribing. GPs saw themselves as the "first port of contact" (16, GP staff) for patients and so their role within GP-VCS collaborations was to signpost patients to appropriate community support. The role of VCS organisations, as an organisation embedded in their communities, was to receive the 'prescribed' patient and provide the holistic, social support that GPs were unable to provide. Public Health and local health commissioners had a role to play breaking down barriers and facilitating relationships.

Across all cases, GP-VCS collaboration was thought to yield positive outcomes, particularly in improving patients' general wellbeing, reducing demand for primary and secondary health services in the city, and challenging 'medicalised' working cultures in General Practice. Improvements in patients' clinical measures were thought to be a possible longer term benefit. All cases were supportive of greater GP-VCS collaboration in the future, although how this was to be achieved was unclear.

\section{Facilitators of collaboration}

Across all cases, GP-VCS collaborations flourished where there was an equal partnership and mutual respect between organisations, including parties recognising and valuing the contribution made by the other in addressing the needs of the community.

“There's something about the fact that we're doing it as a group and a team... and everybody's equal and imputing different points" (Focus Group, VCS staff)

Equitable relationships required a realignment of traditional power roles and for GP staff to adopt a more social model of health; recognising the contribution of VCS organisations and making efforts to "reduce the status gap" (10, GP staff). 
Building on an equal partnership, GP-VCS collaborations benefited from organisations having shared and common aims and objectives that were adopted by all members of staff; "talking the language" (16, GP staff) and being "on the same sort of wavelength" (9, VCS staff). Aims and objectives were likely to be shared when they reflected a clear patient need and both sides had input into the design, with a clear understanding of roles.

Effective GP-VCS collaborations required clear and regular communication between parties. Opportunities for both formal communication (i.e. meetings) and informal interaction between GP and VCS organisation staff were thought to be beneficial. Examples of valuable communication were keeping the other party updated regarding internal organisational changes (i.e. staffing) and feeding back outcomes from referrals. Feedback through both formal updates and informal interactions provided reassurance that the collaboration was productive and built confidence in the relationship.

"Building and maintaining that communication, relationship building, constantly feeding good news information to [the GP] so their ear is constantly pricked up is really key" (12, VCS staff).

Partly because of the beneficial effect in facilitating communication, close physical proximity between partner organisations was repeatedly emphasised as an important factor for GP-VCS collaboration. Physical proximity between GPs and VCS organisations - ultimately as colocation - increased awareness and visibility between GP and VCS organisations.

"You can put up as many posters as you want or send emails about services...but I get the most information that I need from them, or learn more about things, is when we meet in the coffee room" (Focus Group, GP staff). 
Physical proximity was also thought to benefit patients as they were more likely to engage with VCS organisations readily associated with the GP surgery.

“Because it's just a place where obviously people go to the doctors a lot. You know they visit the doctor probably more than they visit a shop. So if we do a health walk form there then the doctors' surgeries are more likely to refer in to us" (12, VCS staff).

Successful GP-VCS collaborations were built on the relationships between people working in both organisations. Relationships were "the thing that makes [GP-VCS collaborations] work" (1, VCS staff). Knowing someone's name, although a small detail, was thought to make collaborative working much more likely. For example, clinicians described referring patients more often to a named person that they know and trust in a VCS organisation.

GP-VCS collaborations were said to require effective leadership; individuals to champion the relationship and drive the collaboration. General practitioners were thought to be key leaders in collaborations because of their professional and social standing. Other potential leaders were GP practice managers, VCS organisation managers, senior clinicians, and commissioners in positions to be gatekeepers and facilitate a hospitable environment.

Being built around a local community and local need, drawing on the skills of the community, was thought to be essential for successful GP-VCS collaborations. GP-VCS collaborations were thought to operate best when allowed to develop with the needs of the community and stakeholders.

"Start off small, link yourself to a practice, talk to your workers first so they have got a good idea who to work with engage yourself with that GP, don't promise them 
anything just slowly and gradually build that relationship, institute bits of work, bits of ideas and just grow it from there" (1, VCS staff)

GP-VCS collaborations did not materialise immediately but took time for sufficient trust to develop between partners. The VCS organisations involved here were "established" in their communities and had "stability, that reliability" (16, GP staff) that GP staff valued. Over time collaborations became part of normal working practice.

Having shared systems and governance was thought to benefit GP-VCS collaborations, helping to make work more consistent. Three key areas of sharing were: 1) IT integration, 2) referral pathways, and 3) a single point of contact.

Finally, GP-VCS collaborations “don't come for free” (8, VCS staff) but required specific resources to develop and progress. Resources included time (i.e. for meetings, setting up projects), space (i.e. for meetings, for co-located practitioners), and finance (i.e. for locum cover). Allocating a specific time for GP and VCS organisation staff to meet, although difficult, was akin to "building in permission to do collaboration" (8, VCS staff).

\section{Barriers to collaboration}

A lack of supporting policy and guidance from regional and/or national authorities was cited as a barrier to collaboration, meaning GP-VCS collaborations had "no real structure" (6, VCS staff) and relied on the good will of individuals. However, a potential risk of involvement from regional or national bodies was that overarching policy frameworks would be too 'topdown' and irrelevant or unsustainable at a local level.

Another barrier to collaboration was negative perceptions of VCS organisations and their role in addressing health inequalities held by GP staff. Such attitudes stem from the pre-eminence of a medical model of health - that GPs "have got all the answers" (11, VCS staff) - and a 
misunderstanding of 1) the underlying socio-economic determinants of health and 2) VCS organisations. Where VCS organisations were seen by GP staff as only able to contribute "on the edge" (15, GP staff) of core services, then collaboration became something additional rather than complementary to their work.

"The difference between wellbeing and you know sending somebody to speak to a health trainer about their weight is very different from sending them to you know into community mental health basically" (13, GP staff)

Negative perceptions and/or misconceptions may also be held by patients. Cultural views of certain medical issues (i.e. mental health) or of VCS practices (i.e. peer-support) may prevent some patients from engaging with VCS organisations. VCS organisations being of their communities raised potential issues concerning professional boundaries for staff who lived and worked in the same community.

GP-VCS collaborations required two potentially different working cultures to merge. The community development principals of VCS organisations opposed those of a GP's medial model. This distinction manifest with regard to individual and organisational relationships with patients and the use of building space. At worst, VCS organisations were viewed as unprofessional.

"There is a certain relationship between a clinician and a patient and then suddenly the patient is a colleague in effect... We were having urgent meetings. 'We need to stop [the VCS organisation] from being anywhere in this building apart from their one office!'” (Focus Group, GP staff) 
Similarly, patient confidentiality and data protection were notable barriers to collaboration between GPs and VCS organisations. GPs were concerned about VCS organisations' unsolicited access to patient records.

Limited capacity and resources were barriers to planning, implementing, and developing collaborations for GP and VCS organisations. Resources included time to invest in collaborations, physical space for meetings and to deliver interventions, and capacity to make and/or receive referrals.

"It's massively challenging for us I think... and I guess for them as well because it's so phenomenally busy so that even to stop and take a breath and look what's beyond what we're doing is I think quite challenging" (14, GP staff)

Demonstrate outcomes from GP-VCS collaborations was challenging. This burden fell particularly on VCS organisations who needed to convince GPs of the value of working together and commissioners of the value of providing funding and support in "a language that [they] will understand" (6, VCS staff).

GP-VCS collaborations were hindered by a lack of awareness of the role of VCS organisations and about of what resources were available in the community. GPs were "out of touch" (17, GP staff) with community resources and lacked the time to invest in new relationships.

“I struggle because I don't know what's out there and finding out in the context of a ten-minute appointment with a patient in front of you...you're dead in the water. You haven't got time to be thinking 'well, where do I ring to find out anyway?', (14, GP staff) 
Finally, GP-VCS collaborations appeared to suffer because of an actual and/or perceived lack of continuity, both across the VCS sector as a whole and within individual GPs and VCS organisations. Short term funding for VCS organisations resulted in an "unintended unreliability" (15, GP staff); GPs may be reluctant to invest in relationships that may be subject to change. Whilst the VCS organisations involved in this research were 'community anchor organisations' embedded in their communities - in contrast to VCS organisations that parachute in and out to deliver specific contracts - they were still viewed with scepticism such that it is not worth GP staff investing in relationships.

"Over the years...I can see this look and people saying 'thank you, thank you for coming'... people want to engage with [VCS organisations] but are thinking 'if I use any energy to do this it's not going to be worth it'," (14, GP staff).

High staff turnover within both GPs and VCs organisations inhibited the development of trusting relationships.

\section{Discussion}

Following a qualitative case study approach, this research has explored the experience of four pairs of GPs and VCS organisation currently involved in collaborative working. Whilst there were similarities across the cases in their use of, for example, Health Trainers and social prescribing, each developed collaborations unique to, and reflective of, their current needs, resources, and local contexts. Collaboration had been 'normalised' to varying degrees across the cases. Three of the cases were engaged in 'light' or 'medium' collaboration (Kimberlee, 2015) built around a transaction of services, whilst the fourth was a more 'holistic' collaboration in which the VCS organisation and GP were physically located in the same 
building and strategically and operationally embedded with one another (Whitelaw et al., 2016).

In terms of the factors affecting collaboration, the findings echo that of previous work specific to GPs and VCS organisation collaboration and the broader partnership working literature. An understanding of the role of individual actors in the delivery of an intervention (White et al., 2010) is perhaps a minimum of what is needed for GPs and VCS organisations to work together. For collaboration to become more 'holistic' and 'embedded', a shared set of beliefs and values is required (White et al., 2017; Whitelaw et al., 2016). Whilst primary care may be resistant to change (Morténius et al., 2012; Ross \& Kettles, 2012), a strong evidence base (Bungay \& Clift, 2010) and being built around a clear local need may support a shared understanding and trust between organisations. Personal relationships between staff members across organisations are the foundation of collaborations (White et al., 2017; White et al., 2010) and opportunities for meaningful formal and informal communication are needed to support the development of relationships. Both GPs and VCS organisations need to be sufficiently resourced to devote time and effort to collaborative working (Goldberg et al., 2013; South et al., 2008). In order to provide a dependable service that GPs can trust, consistent funding for VCS organisations is needed (Brandling \& House, 2007). Whilst the importance of skilled link workers to facilitate between patients, GPs and VCS organisations has been stressed elsewhere (Mossabir et al., 2015), this relates to one particular format of social prescribing. More generally, collaborators need clear and shared processes with regard to referral pathways and data sharing. Physical proximity between organisations may promote GP-VCS collaboration (Mossabir et al., 2015; Woodall \& South, 2005), enabling greater communication between staff and making the 'prescription' easier for patients. Beyond individual organisations, a supportive policy environment and legislative context is important (Clay \& Stern, 2015; Kimberlee et al., 2014; Whitelaw et al., 2016) 
That effective GP-VCS collaboration, takes time, requires a level of trust between partners, strong leadership, and the 'negotiation' of professional boundaries is perhaps unsurprising given the large body of pre-existing evidence in the broader literature. Indeed, using Hudson \& Hardy's (2002) framework for partnership working, for example, we can easily map out how GP-VCS collaboration requires both sides to 1) acknowledge the need for partnership, 2) share a clarity and realism of purpose, 3) commit to and have ownership of the endeavour, 4) develop and maintain trust, 5) establish clear and robust systems and governance, and 6) monitor and review organisational learning.

The implication that GP-VCS collaboration might be achieved formulaically is good news for those championing linking GPs with resources in their communities as a solution to the 'wicked problems' facing primary care; a way to do more with less and address the psychosocial needs of patients, especially in deprived communities. The ' 5 Year Forward View' (NHS England, 2014) and 'General Practice Forward View' (NHS England, 2016) both recognise previous systemic failures to address health inequalities and promote greater collaboration between public, private, and voluntary sector partners. At a local level in Sheffield, the Health Inequalities Group within the CCG has attempted to bring together an 'alliance of the willing' to start a dialogue around the collaborative practice already going on in the city. However, whilst the current policy environment may appear amenable to collaboration, and high profile examples of GP-VCS collaboration, such as Rotherham Social Prescribing (Dayson \& Bashir, 2014), are celebrated, significant issues remain to be resolved. Firstly, GPs and VCS organisations are likely to have opposing norms and values with regard to the causes of, and solution to, the healthcare needs of communities, which need to be reconciled for GP-VCS collaborations to develop (Aveling \& Jovchelovitch, 2014; White et al., 2017). This conflict of medical and social models reflects Bryson et al's (2006) notion of 
'competing institutional logic', whereby actions, processes, norms, and structures that are perceived as legitimate from one perspective may be seen as less legitimate from another. The necessary re-orientation of power and roles may be optimal where the hegemony of the medical model is reduced in favour of a socially orientated perspective more suited to addressing the psycho-social health and wellbeing needs of deprived communities. However, the extent to which those on the 'medical' side are willing, or able, to hand over some of their power and control to those on the 'social' side (i.e. VCS organisation, public health) is unclear. It would appear that the current approach is to rely on the good intentions of individuals as there is little in the way of systemic mechanisms to encourage alternative ways of thinking and working among medical practitioners. GPs are in a position to provide the strong leadership to achieve the necessary cultural shift in general practice towards more holistic, psycho-social models of care (Brandling \& House, 2007; Mossabir et al., 2015; White et al., 2017; Whitelaw et al., 2016). Those leading collaborations need to be able to surrender some of their autonomy in favour of the greater good of the populations they collectively serve, as well as embrace uncertainty, unpredictability and experimentation, and to adapt quickly to what works (Ham \& Brown, 2015). Whilst learning about health inequality and the social determinants of health are included in the undergraduate medical curriculum, for example, this information is vague and there is no assessment of how it is to be delivered.

Secondly, the voluntary and community sector is not a homogenous block but incorporates a diverse range of organisations. Those involved in this research can be broadly considered 'community anchor organisations'. They have been established as hubs for activities and services in their communities for a number of years and are relatively formalised/funded, compared to informal community groups. The challenges of collaboration with and for this 
latter group may well be very different when compared to co-working with paid staff with relatively large organisational systems behind them.

Thirdly, collaboration is being encouraged at a time when substantial cuts are being made to the voluntary and community sector. Whilst it may be acceptable for the initial stages of new collaborations to increase workloads, moving forward collaborations need to be at least 'time-neutral' for all involved (Clay \& Stern, 2015; GPs at the Deep End, 2014). In order to provide a dependable service that GPs can trust, consistent funding for VCS organisations is needed (Brandling \& House, 2007). There is a slight irony in one of the proposed to address the growing economic crisis in primary care (i.e. GP-VCS collaboration), itself, not being appropriately funded.

Fourthly, the motivations of parties entering a collaboration can have short- and long-term implications for the success of the collaboration. Evidence suggests there are two broad reasons for collaboration: participants either 'fail' into their role in the collaboration (i.e. they cannot get what they want without collaborating) or because collaboration is assumed to be a superior way of working with little attention paid to the difficulties or costs (Bryson et al., 2006; Slater et al., 2007). The extent to which GPs and VCS organisations are - or feel they are - being 'forced' or coerced to collaborate by external financial or political pressures is significant and needs to be considered if more 'holistic' GP-VCS collaborations are to develop and become embedded.

\section{Strengths and limitations}

Data were taken from qualitative case studies and, as such, conclusion were not meant to be entirely generalisable to other contexts. It is a limitation of much of the wider evidence on GP-VCS collaborations that it is anecdotal and drawn from small scale research/evaluations. In this case, the in-depth nature of the research and iterative process of analysis means that 
key points of learning may be extrapolated beyond the individual cases. The four cases were comprised of pairs of GPs and a VCS organisation with whom they work to address health inequalities in their communities. Including GPs and VCS organisations not engaged in coworking may have further illuminated some of the tensions associated with collaboration.

\section{Conclusion}

There is a broad appetite and willingness among GPs and VCS organisations to collaborate and an increasing mandate from policy makers and national bodies for those organisations to work together in order to address the 'wicked problems' facing primary care. The wider literature on partnership working is well developed, yet there is little good quality evidence to inform GP-VCS collaborations in practice. Reflecting on the experience of four pairs of GPs and VCS organisations currently engaged in various forms of collaboration, this paper identified factors that aid or inhibit collaboration. These echo the findings of previous service evaluations and the wider partnership working literature. Whilst current political rhetoric represents an opportunity to develop collaborations, issues remain. Local service models may develop on an ad hoc basis, but it is not sustainable to rely on individual initiative alone; financial pressures, growing inequalities and demographic change mean that more systemic action needs to be taken. The initial pathways to, and development pathways within, GP-VCS collaborations need to be more clearly understood. The outcomes and value-for-money of different models of collaboration also need to be more rigorously assessed - beyond the anecdotes and small scale research/evaluations that make up most of the evidence base before conclusions as to the impact of GP-VCS collaboration on health outcomes can be made. 


\section{References}

Age UK Yorkshire \& Humber. (2012). Social Prescribing. A model for partnership working between primary care and the voluntary sector: Age UK Yorkshire \& Humber.

Aveling, E. L., \& Jovchelovitch, S. (2014). Partnerships as knowledge encounters: a psychosocial theory of partnerships for health and community development. J Health Psychol, 19(1), 3445.

Baird, B., Charles, A., Honeyman, M., Maguire, D., \& Das, P. (2016). Understanding pressures in general practice. London: The King's Fund.

Bickerdike, L., Booth, A., Wilson, P. M., Farley, K., \& Wright, K. (2017). Social prescribing: less rhetoric and more reality. A systematic review of the evidence. BMJ Open, 7(4), e013384-e013384.

Brandling, J., \& House, W. (2007). Investigation into the Feasibility of a Social Prescribing Service in Primary Care: A Pilot Project. Bath: University of Bath and Bath and North East Somerset NHS Primary Care Trust.

Braun, V., \& Clarke, V. (2006). Using thematic analysis in psychology. Qualitative Research in Psychology, 3(2), 77-101.

Bryman, A. (2016). Social research methods: Oxford, United Kingdom : Oxford University Press.

Bryson, J. M., \& Crosby, B. C. (2005). Leadership for the common good: tackling public problems in a shared-power world. San Francisco: Jossey-Bass.

Bryson, J. M., Crosby, B. C., \& Stone, M. M. (2006). The Design and Implementation of Cross-Sector Collaborations: Propositions from the Literature. Public Administration Review, 66, 44-55.

Bungay, H., \& Clift, S. (2010). Arts on Prescription: A review of practice in the UK. Perspectives in Public Health, 130(6), 277-281.

Cawston, P. (2011). Social prescribing in very deprived areas. The British Journal Of General Practice: The Journal Of The Royal College Of General Practitioners, 61(586), 350-350.

Clay, H., \& Stern, R. (2015). Making Time in General Practice. London: Primary Care Foundation \& NHS Alliance.

Coe, C., \& Barlow, J. (2010). Working in partnership with the voluntary sector: Early Explorer clinics. Community Practitioner, 83(11), 33-35.

Dayson, C., \& Bashir, N. (2014). The social and economic impact of the Rotherham Social Prescribing Pilot. Sheffield: University of Sheffield.

Dayson, C., Bashir, N., \& Pearson, S. (2013). From dependence to independence: emerging lessons from the Rotherham Social Prescribing Pilot. Sheffield: University of Sheffield.

Douglas, A. (2009). Partnership Working. London: Taylor \& Francis.

Friedli, L., Themessl-Huber, M., \& Butchart, M. (2012). Evaluation of Dundee Equally Well Sources of Support: Social Prescribing in Maryfield.

Goldberg, D. G., Mick, S. S., Kuzel, A. J., Feng, L. B., \& Love, L. E. (2013). Why Do Some Primary Care Practices Engage in Practice Improvement Efforts Whereas Others Do Not? Health Services Research, 48(2pt1), 398-416.

GPs at the Deep End. (2010). Deep End Report 8. Social Prescribing. Glasgow: University of Glasgow.

GPs at the Deep End. (2014). Deep End Report 25. Strengthening primary care partnership responses to the welfare reforms. Glasgow: University of Glasgow.

Grant, C., Goodenough, T., Harvey, I., \& Hine, C. (2000). A Randomised Controlled Trial and Economic Evaluation of a Referrals Facilitator between Primary Care and the Voluntary Sector, 419.

Ham, C., \& Brown, A. (2015). The Future is Now. London: The King's Fund.

Hudson, B., \& Hardy, B. (2002). What is a 'successful' partnership and how can it be measured? . In C. Glendenning, M. Powell, \& K. Runnery (Eds.), Partnerships, New Labour and the Governance of Welfare. Bristol: The Policy Press.

Kimberlee, R. (2013). Developing a social prescribing approach for Bristol. Bristol: Bristol Health and Wellbeing Board. 
Kimberlee, R. (2015). What is social prescribing? Advances in Social Science Research Journal, 2(1)

Kimberlee, R., Ward, R., Jones, M., \& Powell, J. (2014). Measuring the economic impact of Wellspring Healthy Living Centre's Social Prescribing Wellbeing Programme for low level mental health issues encountered by GP services. Bristol: University of the West of England.

Lamb, J., Bower, P., Rogers, A., Dowrick, C., \& Gask, L. (2012). Access to mental health in primary care: a qualitative meta-synthesis of evidence from the experience of people from 'hard to reach' groups. Health (London), 16(1), 76-104.

Lindsay, C., \& Dutton, M. (2012). Promoting Healthy Routes Back to Work? Boundary Spanning Health Professionals and Employability Programmes in Great Britain. Social Policy \& Administration, 46(5), 509-525.

Löffler, C., Koudmani, C., Böhmer, F., Paschka, S. D., Höck, J., Drewelow, E., . . Altiner, A. (2017). Perceptions of interprofessional collaboration of general practitioners and community pharmacists - a qualitative study. BMC Health Services Research, 17, 1-7.

Lowndes, V., \& Skelcher, C. (1998). THE DYNAMICS OF MULTI-ORGANIZATIONAL PARTNERSHIPS: AN ANALYSIS OF CHANGING MODES OF GOVERNANCE. Public Administration, 76(2), 313.

Maughan, D. L., Patel, A., Parveen, T., Braithwaite, I., Cook, J., Lillywhite, R., \& Cooke, M. (2016). Primary-care-based social prescribing for mental health: an analysis of financial and environmental sustainability. Primary Health Care Research \&amp; Development, 17(2), 114121.

May, C., Finch, T., Mair, F., Ballini, L., Dowrick, C., Eccles, M., . . Heaven, B. (2007). Understanding the implementation of complex interventions in health care: the normalization process model. BMC Health Services Research, 7(1), 148.

Morténius, H., Fridlund, B., Marklund, B., Palm, L., \& Baigi, A. (2012). Utilisation of strategic communication to create willingness to change work practices among primary care staff: a long-term follow-up study. Primary Health Care Research \&amp; Development, 13(2), 130141.

Mossabir, R., Morris, R., Kennedy, A., Blickem, C., \& Rogers, A. (2015). A scoping review to understand the effectiveness of linking schemes from healthcare providers to community resources to improve the health and well-being of people with long-term conditions. Health \& Social Care in the Community, 23(5), 467-484.

NHS Commissioners across South and Mid Yorkshire, B., and North Derbyshire, . (2017). Health and care in South Yorkshire and Bassetlaw: Sustainability and Transformation Plan. Sheffield: NHS England.

NHS England. (2014). Five Year Forward View. London: NHS England.

NHS England. (2016). General Practice Forward View. London: NHS England.

Pavey, T. G., Taylor, A. H., Fox, K. R., Hillsdon, M., Anokye, N., Campbell, J. L., . . Taylor, R. S. (2011). Effect of exercise referral schemes in primary care on physical activity and improving health outcomes: systematic review and meta-analysis, 980.

Pedersen, H. B., Helmer-Nielsen, M., Dieperink, K. B., \& Østergaard, B. (2016). Exercise on Prescription: A Cross-sectional Study With Self-reported Outcome. Journal of Physical Activity \& Health, 13(4), 377-384.

Popay, J., Kowarzik, U., Mallinson, S., Mackian, S., \& Barker, J. (2007). Social problems, primary care and pathways to help and support: addressing health inequalities at the individual level. Part I: the GP perspective. Journal of Epidemiology and Community Health, 61(11), 966-971.

Primary Care Workforce Commission. (2015). The future of primary care: Creating teams for tomorrow. London: Health Education England.

Ross, J. D., \& Kettles, A. M. (2012). Mental health nurse independent prescribing: what are nurse prescribers' views of the barriers to implementation? Journal of Psychiatric \& Mental Health Nursing, 19(10), 916-932. 
Slater, R., Frederickson, J., Thomas, C., Wield, D., \& Potter, S. (2007). A critical evaluation of partnerships in municipal waste management in England. Resources, Conservation \& Recycling, 51, 643-664.

South, J., Higgins, T., Woodall, J., \& White, S. (2008). Can social prescribing provide the missing link? Primary Health Care Research \&amp; Development, 9(4), 310-318.

Swindley, S. (2015). Is it time to look at the third sector afresh? Retrieved from http://www.kingsfund.org.uk/blog/2015/06/it-time-look-third-sector-afresh

White, J., Cornish, F., \& Kerr, S. (2017). Front-line perspectives on 'joined-up' working relationships: a qualitative study of social prescribing in the west of Scotland. Health \& Social Care in the Community, 25(1), 194-203.

White, J., Kinsella, K., \& South, J. (2010). An Evaluation of Social Prescribing Health Trainers in South and West Bradford. Leeds: Leeds Beckett University.

Whitelaw, S., Thirlwall, C., Morrison, A., Osborne, J., Tattum, L., \& Walker, S. (2016). Developing and implementing a social prescribing initiative in primary care: insights into the possibility of normalisation and sustainability from a UK case study. Primary Health Care Research \&amp; Development, 1-10.

Woodall, J., \& South, J. (2005). The Evaluation of the CHAT Social Prescribing Scheme in Bradford South and West PCT. Leeds: Leeds Beckett University. 


\section{Case studies}

\section{Case 1: The White House Surgery - Manor \& Castle Development Trust}

Manor \& Castle Development Trust (MCDT) was established in 1997 to deliver a regeneration programme with local people in one of the most deprived areas of Sheffield, the Manor Castle ward. Underpinned by community development principles, MCDT deliver a range of services, including fitness classes, employment support, social cafes, pre-school, play schemes, youth clubs, and alternative education, and own assets and are landlord for retail shops and flats.

The White House Surgery has been situated approximately two miles away from MCDT in custom built premises since December 2009. The practice serves around 6,300 patients in one of the most deprived communities in the city. The surgery has four GP partners, two salaried GPs and, as a training practice, a varied number of registrars at a given time. The practice has a tradition of working with voluntary groups, having been a part of the Manor Neighbourhood Team and holding a seat on an earlier 'Manor Forum' board.

The relationship between MCDT and The White House Surgery began in 2011 with MCDT approaching The White House Surgery. The organisations do no work together exclusively and there is no contract or service level agreement between MCDT and The White House Surgery, although they are both part of a consortia to address health inequity in the local area.

\section{Case 2: Hanover Medical Centre - Shipshape}

Hanover Medical Centre is located just outside the city centre and is part of a two-site practice that serves roughly 6,500 patients (combined). The practice serves an ethnically diverse population with significant mental health and drug and alcohol problems. The practice is a consistent 'hub' that has built up trust with the community over many years.

Shipshape is located just over one mile from Hanover Medical Centre. They deliver three core strands of work targeted on areas of deprivation: 1) Health Trainers; 2) a community wellbeing programme; and 3) Health Champions and volunteering. They follow community development principals to get the community involved in their work and bring people together.

Hanover Medical Centre have a Somali link worker funded by Shipshape and Shipshape also provide a Health Trainer to Hanover Medical Centre to provide more in-depth support to patients about weight management, smoking cessation, diet, exercise, and alcohol. Hanover Medical Centre and Shipshape do not work exclusively together. The two organisations are not formally contracted to each other but work together on an ad hoc basis. 


\section{Case 3: High Green Health Centre - SOAR}

SOAR is a community regeneration charity and community anchor organisation based in north Sheffield that started in 1999. They provide a range of services designed to improve the health, wellbeing and employability of the community. SOAR is also involved in a small amount of commissioning and facilities management.

Located approximately four miles away in the north Sheffield ward of Ecclesfield, High Green Health Centre is part of the two-site Chapelgreen Practice. Together they serve approximately 16,000 patients, have eight partner GPs and employ around forty members of staff, including 3-4 salaried GPs and six training doctors. The local patient population contains a large number of elderly people and prominent health issues are those associated with aging. High Green Health Centre was described as a source for patients in addressing ill-health and a lynch pin for other organisations in the community.

SOAR has working relations with approximately 20 GP practices across the north of Sheffield, principally through social prescribing and the provision of Health Trainers. Similarly, High Green Health Centre work with a number of VCS organisations, including SOAR and Age UK. High Green Health Centre make use of SOAR as a referral agency and there is limited meetings and dialogue about new initiatives between the organisations.

\section{Case 4. Darnall Primary Care - Darnall Wellbeing}

A GP surgery in Darnall in the east of Sheffield was established in 1980 and the practice became salaried in 1997 as part of a larger NHS body. As of 2015, the practice has been run jointly by Sheffield Health and Social Care Trust and Primary Care Sheffield as part of the four-site Clover Group. From its inception, what has become Darnall Primary Care Centre has always adopted progressive strategies for addressing local health inequalities.

Darnall Wellbeing was established by staff from Darnall Primary Care and so the organisations have always been affiliated. Darnall Wellbeing began in 2000 as one parttime person delivering social prescribing from the Darnall Primary Care Practice. The first contractual working between an incorporated Darnall Wellbeing and Darnall Primary Care Centre concerned Practice Champions in 2013. The same year Darnall Wellbeing became co-located alongside Darnall Primary Care, Clover Group administration, nursing services, community therapies and a pharmacy in the Darnall Primary Care Centre. In 2014, Clover Group, Darnall Wellbeing, Sheffield CCG, and Sheffield Public Health established the Enhanced Primary and Community Care (EPCC) scheme. EPCC is a mechanism for primary care staff to make referrals using SystmOne to the EPCC project coordinator, which then get cascaded a Darnall Wellbeing Health Trainer, Community Support Worker, or other Darnall Wellbeing service as appropriate. Darnall Wellbeing staff also access to the system in order to provide timely feedback. 


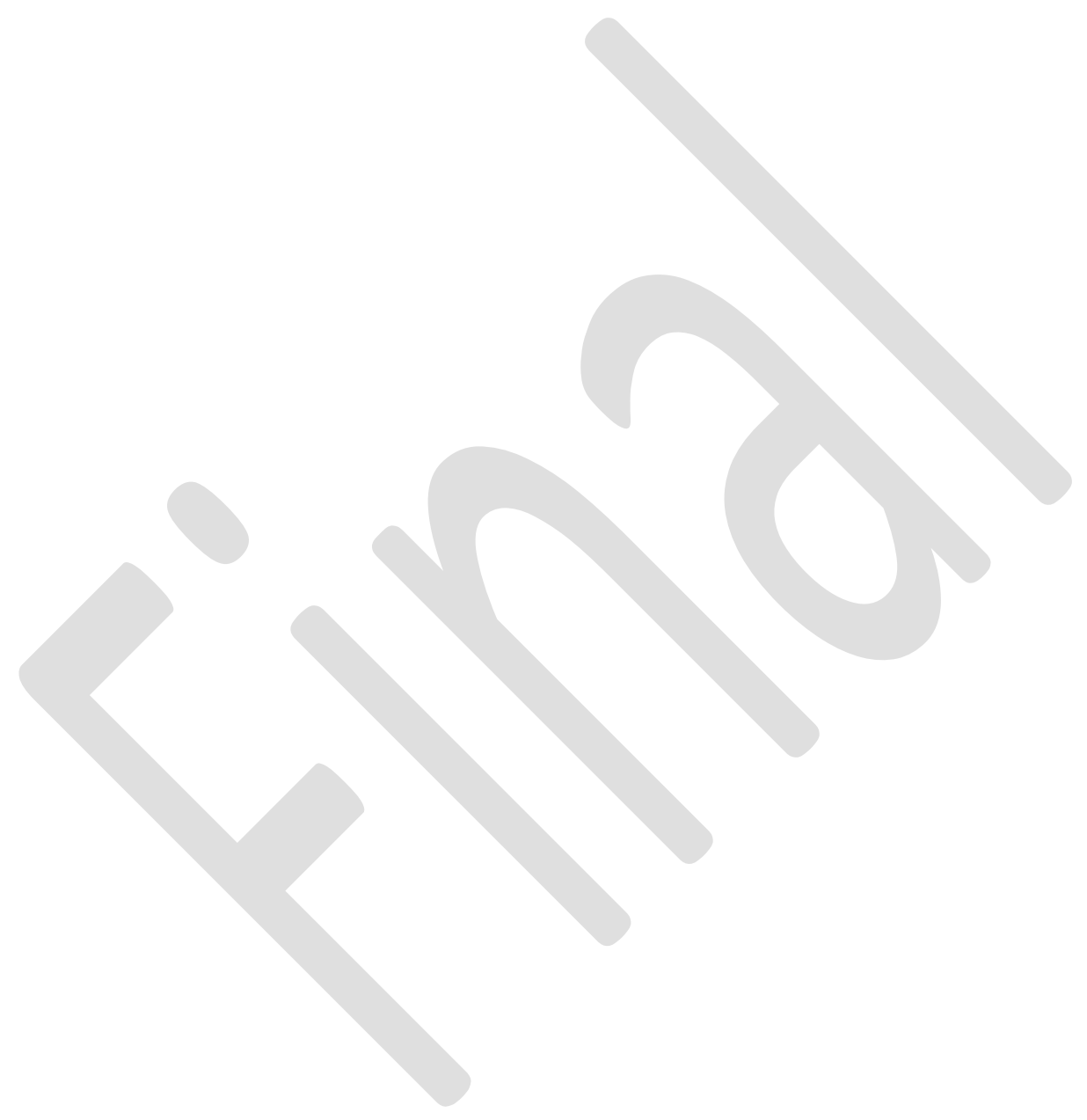

